\title{
La elección de la marca del distribuidor en productos duraderos: factores de influencia ${ }^{1}$
}

\section{The selection of private brand durable goods: factors affecting the Choice}

\author{
Eva M. ${ }^{a}$ Caplliure Giner

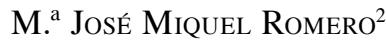 \\ Carmen Pérez Cabañero
}

Universitat de València

Recibido el 10 de diciembre de 2009, aceptado el 20 de abril de 2010

$\mathrm{N}^{\mathrm{o}}$ de clasificación JEL: M30

DOI: $10.5295 / \mathrm{cdg} .100194 \mathrm{ec}$

Reseña bibliográfica: CAPLLIURE, E. M.; MIQUEL, M. J. y PÉREZ, C. (2010): “La elección de la marca del distribuidor en productos duraderos: factores de influencia", Cuadernos de Gestión, Vol 10, no especial, pp. 125-147, DOI: 10.5295/cdg.100194ec

\section{Resumen:}

La apuesta de la distribución por la extensión de su marca a las categorías de productos duraderos, como electrodomésticos y productos electrónicos para el hogar, ha demostrado ser acertada, a pesar de las críticas en contra de esta estrategia. Posiblemente, la mayor familiaridad del consumidor con las marcas del distribuidor, el cambio de actitud favorable hacia éstas, la disponibilidad de la tecnología, y por qué no, la crisis económica internacional que afecta a las economías domésticas, pueden ser factores explicativos de este éxito. El escaso número de trabajos que tratan de explicar las razones de aceptación de estas marcas en productos duraderos nos ha llevado a plantear si las variables que determinan la compra de la marca del distribuidor en categorías de estudio clásicas como son las de alimentación y droguería, son de aplicación en el caso de productos duraderos. Los resultados preliminares indican que no.

Palabras clave:

Marca del distribuidor, intención de compra, productos duraderos, familiaridad, actitud y satisfacción

\begin{abstract}
:
Distributors have extended their brand policy to durable good categories such as household appliances and electronic devices, what has been proved to be worthy, although it has received a lot of criticism. Possibly, the higher familiarity of the consumer with private brands, the favourable change of attitude towards them, the availability of technology and, why not, the actual international economic crisis which affects to the domestic economies can be factors which explain this success. The few researches trying to explain the reasons of acceptance of these brands in durable goods have taken us to analyze whether factors determining the purchase of private brands in typical study categories such as food and cosmetics can be applied to durable goods. Preliminary results indicate that it is not possible.
\end{abstract}

\section{Keywords:}

Store brand, purchase intention, durable goods, familiarity, attitude and satisfaction

\footnotetext{
${ }^{1}$ Esta investigación ha sido financiada por el proyecto GV 2009-019 de la Generalitat Valenciana.

2 Maria.J.Miquel@uv.es
} 


\section{INTRODUCCIÓN}

Desde la aparición de los primeros productos con marca del distribuidor a finales del siglo XIX, las marcas de la distribución han ido incrementando su presencia en todo el mundo de forma imparable. Si bien en algún momento del siglo pasado se predijo que ya habían alcanzado su máxima participación, los datos de hoy en día muestran que su participación sigue creciendo tanto en volumen de unidades como en valor, así como en número de categorías de productos en las que está presente. Según el Anuario Internacional de la Marca del Distribuidor 2008 publicado por la Private Label Manufacture Association (PLMA) y elaborado por Nielsen, las marcas del distribuidor han logrado incrementar su participación en los 18 países europeos sobre los que se realizó el estudio, alcanzando en algunos de ellos más del $40 \%$ de participación, como es el caso de Bélgica, Reino Unido y Suiza.

El estudio de Ipsos Mori para la PLMA pone de manifiesto un cambio de actitud del consumidor hacia este tipo de marcas, que lleva a los consumidores a aceptar estas marcas por razones distintas al precio, las condiciones económicas o la modalidad de venta. De hecho, el porcentaje de compradores que afirman que comprarán más marcas de distribuidor supera con creces la cifra de consumidores que afirman que comprarán cantidades menores, lo que sigue sugiriendo un incremento de su participación. También se ha identificado un enorme grupo de consumidores "habituales" de marcas de distribuidor. Adicionalmente, los consumidores consideran que los productos de marcas de distribuidor tienen la misma calidad que las marcas de fabricantes (PLMA, 2008).

Nuevos formatos comerciales de éxito como los category killers, son un claro ejemplo de la expansión de la marca de la distribución a nuevas categorías de productos, no sólo de alimentación y droguería. Según puso de manifiesto el Observatorio de la Distribución 2004, estos establecimientos se están convirtiendo en los lugares preferidos para la compra de muebles (alrededor del $42 \%$ de los individuos lo prefiere), electrodomésticos (un 33\%), equipamiento deportivo $(33,7 \%)$ e informática de uso doméstico $(47,4 \%)$, logrando ganar posiciones sobre el hipermercado y el pequeño comercio (Uriel, 2004). Su base de negocio está en el desarrollo de su propia marca en casi todas, por no decir en todas, las líneas de producto que comercializan, lo que les permite ofrecerlos a precios razonables.

Así pues, si hasta ahora las marcas del distribuidor estaban comúnmente asociadas a los establecimientos de alimentación y droguería, a partir de ahora habrá que considerarlas en el caso de los productos duraderos, especialmente en los productos electrónicos de consumo y electrodomésticos para el hogar, que son los sectores que han presentado un mayor dinamismo a este respecto en los últimos años (Nielsen, 2008). En el año 2000, las marcas del distribuidor en el mercado de aparatos electrónicos en Estados Unidos suponían el 36\% de las ventas del mercado de aparatos electrónicos en dicho país (Steiner, 2004). En los últimos años, detallistas como Best Buy y Wal-Mart han acudido a países con menores costes de fabricación para la elaboración de sus propios electrodomésticos, lo que les ha proporcionado elevados márgenes y ha obligado a los responsables de las marcas de fabricante a disminuir sus precios por el incremento de la competencia. Para los consumidores, el incremento de la competencia, particularmente en el segmento de precios bajos, ha sido un boom.

Ante este nuevo escenario de éxito indiscutible de las marcas de la distribución en las nuevas categorías de productos en las que han sido introducidas, especialmente en las 
de productos duraderos (electrodomésticos para el hogar, productos electrónicos, juguetes,...), sorprende la escasa literatura sobre marcas del distribuidor en dichas categorías. Asimismo, en la literatura suelen destacarse las diferencias existentes en el comportamiento del consumidor según su proceso de compra se refiera a bienes de compra frecuente o a bienes duraderos. Ambas circunstancias nos han llevado a plantear la necesidad de analizar qué variables son determinantes en la elección de la marca del distribuidor en la compra de bienes duraderos.

Por tanto, partiendo de las relaciones que en investigaciones previas se confirman para explicar la compra de marca del distribuidor en productos de alimentación y droguería, se pretende estudiar si estas relaciones son válidas también para explicar el comportamiento de compra de marca del distribuidor en bienes duraderos. Así pues, tras comentar en la exposición del marco conceptual las diversas aportaciones recientes en torno a la gestión e investigación de las marcas del distribuidor, se proponen trece hipótesis debidamente justificadas acerca de las relaciones existentes entre determinadas variables destacadas en la literatura, como por ejemplo la familiaridad, satisfacción, actitud e intención de compra de la marca del distribuidor. Comentada la metodología y contrastadas las hipótesis, se analizan los resultados obtenidos, planteando asimismo las implicaciones gerenciales derivadas de dichos resultados. Consideramos que el presente trabajo supone una contribución a nivel académico y de gestión dada la escasez de estudios empíricos en torno al comportamiento de compra del consumidor de la marca del distribuidor en bienes duraderos.

\section{MARCO CONCEPTUAL E HIPÓTESIS}

La entrega de valor al consumidor por parte de los distribuidores pasa por dar una respuesta más apropiada a las expectativas de los consumidores (Miranda y Joshi, 2003). Si bien el precio es un elemento clave a la hora de comunicar el valor del producto al consumidor (Dickson y Sawyer, 1990), hay otros elementos generadores de valor, como es la calidad, que comienzan a ser más importantes. Las marcas del distribuidor (MD) tratan de combinar precio y calidad, junto con otros elementos, para ofertar un mayor valor a los consumidores (Apelbaum, Gerstner y Naik, 2003). Los distribuidores buscan que sus consumidores perciban sus marcas como de igual o mejor calidad, menos caras o de precio similar al resto de marcas comercializadas en el mercado, y lo están consiguiendo, tal y como se desprende del informe de Ipsos Mori (PLMA, 2008).Los distribuidores han adoptado como estrategia la construcción de valor de marca (Pappu y Quester, 2006), lo que les genera múltiples beneficios, que junto con la experiencia adquirida, les permite comercializar con éxito cualquier producto, es decir, desde productos de compra frecuente a productos duraderos, de productos básicos a productos de conveniencia, de productos utilitarios a productos hedónicos, o desde productos con tecnologías relativamente simples a productos altamente tecnológicos.

Para ello, los gestores de la MD tradicionalmente han optado por bien comercializar los productos con la enseña, logo, emblema del distribuidor (estrategia de marca cadena o del distribuidor) o bien comercializarlos con un nombre no asociado a la enseña y que es de su propiedad (estrategia de marca privada). En ambos casos, la puesta en marcha por parte del distribuidor de un excelente programa de marcas le aporta, además de importantes retornos 
de la inversión (ROI), ventajas como el desarrollo de clientes leales, creación de imagen de marca, diferencias competitivas, mayor flexibilidad, y ofrecer al consumidor más información y una mayor garantía de los productos (Hoch, 1996; Dhar y Hoch, 1997; Recio y Róman, 1999; Narasimhan y Wilcox, 1998; Nandan y Dickinson, 1994; Davies, 1998; Oubiña, Rubio y Yagüe, 2006). La creación de una proposición única de venta para un rango específico de MD es la estrategia adecuada (Gutwilling, 2000; Steiner, 2004), puesto que no siempre los consumidores distinguen entre las marcas del distribuidor de distintas cadenas (Richardson, 1997), y el incremento de la presencia de la marca del distribuidor en un mayor número de categorías favorece las ventas de ésta (Sayman y Raju, 2004).

Desde el punto de vista académico podemos distinguir tres líneas de investigación relacionadas con la marca del distribuidor. La primera referente al comportamiento de compra (que es la línea a la que se ajusta el presente trabajo), la segunda centrada en las estrategias seguidas por los distribuidores (e.g. Puelles y Manzano, 2009) y tercera, la respuesta de los fabricantes (e.g. Méndez, Oubiña y Rozano, 2000; Fernández, Gómez y Rubio 2003; Oubiña, Rubio y Yagüe, 2006).

Centrándonos en la primera línea de investigación, podríamos afirmar que la literatura existente ya es cuantiosa, si bien consideramos que hay aspectos todavía por aclarar.

Prácticamente todas la investigaciones sobre el comportamiento de compra de la marca del distribuidor y factores determinantes de su elección se han centrado en la compra de productos de alimentación, bebidas, droguería y perfumería (Garretson et al, 2002; Burton y Lichtenstein, 1998; Putsis y Dhar, 2001; Sethuraman, 1992; Narsimhan y Wilcox, 1998; Sinha y Batra, 1999; Miquel, Caplliure y Aldas, 2002; Richardson et al, 1997), categorías propias de establecimientos de descuento, supermercados e hipermercados; los estudios desarrollados han dejado bastante de lado el análisis de otras categorías como ropa, calzado o electrónica, entre otras, en las que las aportaciones son esporádicas (d'Astous y SaintLouis, 2005; Vahie y Paswan, 2006) y por las que los distribuidores están apostando al reconocer los beneficios tanto financieros como de marketing de estos productos.

En concreto los productos duraderos, objeto de estudio en este trabajo, son productos generalmente de alta implicación, con alto riesgo asociado. Se considera que tienen muchas características experienciales, ya que el consumidor valora cómo se va a sentir, cómo le van a juzgar y, además, el individuo tiene expectativas previas, lo que hace más compleja la decisión de compra. De hecho, Batra y Sihnha (2000) sugieren que algunas de las dimensiones del comportamiento de compra de estos productos difieren del comportamiento de compra de los productos corrientes. En el caso concreto de productos con MD, Jin y Suh (2005) constataron diferencias significativas en cuanto a las variables de influencia sobre la intención de compra, entre productos de alimentación y productos electrónicos para el hogar.

Por lo tanto, no cabe duda de que las características del producto y tipo de producto influyen sobre la intención de compra de la MD, como se ha demostrado en otros trabajos con referencia a productos de alimentación (Berkowitz, Bao y Allaway, 2005; Semeijn, Van Rielm y Ambrosini, 2004; Batra y Sinha, 2000; Miquel y Caplliure, 2000; Sethuraman y Cole, 1999).

En el caso español, la mayoría de los distribuidores han optado por el desarrollo de una marca propia para la comercialización de los productos duraderos, lo que dificulta la asociación por parte del consumidor de la marca con el distribuidor; no obstante, claro está, 
dicha asociación depende del nivel de comunicación que el distribuidor haya establecido con el cliente. Así por ejemplo, Decathlon no utiliza su marca sino que utiliza otras marcas como por ejemplo Quechua; Carrefour, para sus electrodomésticos, utiliza la marca Firstline; Conforama utiliza la marca Far para los productos de la línea blanca y marrón, y para muebles e iluminación utiliza la marca Conforama. Es decir, que en el mercado coexisten tanto las estrategias puras de MD como la combinación de ambas dependiendo del tipo de producto (Puelles y Manzano, 2009).

Ante este nuevo escenario, el objetivo del presente trabajo es determinar si las relaciones previamente identificadas entre la intención/probabilidad de compra de productos corrientes con marca del distribuidor y variables tales como actitud hacia la marca del distribuidor, implicación con el producto, satisfacción con la marca del distribuidor en general, experiencia de compra, conciencia de precio o calidad percibida, son relaciones específicas de este tipo de productos concreto, o si bien son generales y de aplicación a cualquier producto, como es el caso de los productos duraderos comercializados con la marca del distribuidor, puesto que estos productos tienen un significado e importancia diferente para el comprador. Aunque son muchas las variables que la literatura previa ha identificado como determinantes de la intención de compra de productos MD, especialmente en productos corrientes, este trabajo se centra en algunas de las que podríamos considerar más habituales de la literatura, no pretendiendo ser, en ningún caso, un estudio exhaustivo de todas las variables abordadas en la literatura existente.

\subsection{Hipótesis}

Una de las principales características de los productos duraderos es el tiempo que transcurre de una compra a otra. Sabemos que la exposición y repetición de compra de la marca del distribuidor incrementa la familiaridad del consumidor con ella (Alba y Hutchinson, 1987; Coupey, Irwin y Payne, 1998). La elección por primera vez de este tipo de marca en una categoría de productos duraderos es un momento crítico, por ello, la elección de esta marca en este tipo de productos dependerá de la experiencia previa en otras categorías de producto con dicha marca (Zielke y Dobbelstein, 2007). Esa mayor experiencia con la marca puede hacer que la confianza del consumidor hacia ella aumente, considerando que ofrece un buen valor, e incrementará, por tanto, la intención de compra de MD (Baltas, 1997). Si bien la naturaleza duradera de los bienes disminuye la experiencia del consumidor con la categoría, no tiene por qué disminuirla con la marca, ya que en el caso concreto de la marca del distribuidor, éste está presente en numerosas categorías de producto, siendo visible, pues, al consumidor. Por tanto:

H1a. Los consumidores familiarizados con la MD en productos corrientes muestran una mayor intención de compra de MD en productos duraderos.

H1b. Los consumidores familiarizados con la MD en productos duraderos muestran una mayor intención de compra de MD en productos duraderos.

Los distribuidores confían en satisfacer las demandas de sus clientes, confían en la calidad de los productos que ofertan, de tal forma que esperan que las experiencias repetidas 
del cliente con la marca ayuden a crear una actitud positiva hacia ésta y una disminución del riesgo percibido (Richardson et al, 1996). Una actitud positiva previa hacia la marca influye positivamente sobre la decisión de compra (Kelmeci-Schneider, 2004; Zielke y Dobbelstein, 2007) por lo que proponemos las siguientes hipótesis:

H2a. La familiaridad con la MD en productos corrientes genera una actitud positiva hacia la MD en general.

H2b. La familiaridad con la MD en productos duraderos genera una actitud positiva hacia la MD en general.

H3. Una actitud positiva hacia la MD en general incrementa la intención de compra de productos duraderos con MD.

Una de las características particulares de las MD es que son comercializadas a un precio inferior a las marcas del fabricante (MF). En los productos duraderos, el precio suele ser un indicador de calidad, por lo que grandes diferencias de precio entre unas marcas y otras da lugar a diferencias significativas en cuanto a la percepción de su calidad (Olson y Jacoby, 1973; Richardson y Dick 1994; Dawar y Parker, 1994). Sin embargo, no todos los consumidores le dan la misma importancia a la variable precio. Entendemos por conciencia del precio el grado en el que el consumidor se centra exclusivamente en pagar lo menos posible (Lichtenstein et al, 1993, pp.235). A priori se podría afirmar que, en el caso de productos de alto riesgo, aquellos individuos que son más conscientes del precio y que perciben que el precio de la MF es injusto, buscarán alternativas más económicas, lo que puede mejorar la actitud hacia la MD e incrementar la probabilidad de compra de los productos con MD (Sinha y Batra, 1999). Dado que el ámbito de estudio del presente trabajo son bienes duraderos, con un alto riesgo asociado, de acuerdo con Burton et al. (1998), planteamos las siguientes hipótesis:

H4a. Una elevada conciencia del precio por parte del consumidor genera una actitud positiva de éste hacia la MD en general.

H4b. Una elevada conciencia del precio por parte del consumidor incrementa la intención de compra de la MD en productos duraderos.

Junto con el precio, la calidad suele ser otra de las principales razones de compra de las MD que la literatura ha puesto de manifiesto, plateándose, además, la interacción entre ambas variables (Hoch y Banerji, 1993; Jin y Suh, 2005). Aunque tradicionalmente las marcas del distribuidor han sido percibidas de inferior calidad a las marcas del fabricante, en los últimos años los minoristas han invertido en el incremento de los estándares de calidad, e incluso han optado, algunos de ellos, por introducir MD Premium (Apelbaum, Gerstner y Naik, 2003), estrategia recomendada recientemente por algunos investigadores (Zielke y Dobbelstein, 2007). La posible diferencia de calidad entre ambas marcas puede ser la principal razón de compra de marca del fabricante en ciertas categorías de producto (Sethuraman y Cole, 1997). Las distintas investigaciones muestran que en la medida en que la diferencia de calidad entre la marca de la distribución y la marca del fabricante sea me- 
nor, mejor es la actitud hacia la marca de la distribución y, por lo tanto, mayor su intención de compra (Hoch y Banerji, 1993; Jin y Suh, 2005). A tenor de lo expuesto se plantean las siguientes hipótesis:

H5a. Una menor percepción de diferencia en calidad entre la MD y la MF genera una actitud positiva hacia la MD en general.

H5b. Una menor percepción de diferencia en calidad entre la MD y la MF incrementa la intención de compra de MD en productos duraderos.

La satisfacción del consumidor con la marca de la distribución es otro factor importante considerado en este trabajo. La relación entre satisfacción e intención de compra ha sido especialmente corroborada en el ámbito de los servicios, al incluir la intención de recompra como parte del constructo lealtad (Cronin y Taylor, 1992; Bolton, 1998): satisfacción y actitud resultan ser los principales antecedentes de la intención de recompra del cliente (Oliver, 1980; Roest y Pieters, 1997). En este sentido, entendemos que comprar MD en productos duraderos puede equipararse a una recompra de $\mathrm{MD}$, si el individuo ya adquiere productos corrientes con MD; por tanto, la satisfacción con la MD en general, redundará positivamente en la actitud hacia esta MD, así como también en la intención de compra de productos duraderos con MD. Además, la literatura desarrollada ha puesto de manifiesto que la satisfacción y la calidad percibida están altamente correlacionadas (Olsen, 2002; Pappu y Quester, 2006), si bien no existe acuerdo sobre la dirección de la relación causal entre ambas variables, encontrándose evidencia en ambos sentidos (Parasuraman et al. 1994; Babakus et al. 2004). En este trabajo partimos de que la calidad percibida es un antecedente de la satisfacción (Cronin y Taylor, 1992), por lo que si el consumidor considera que la diferencia en calidad entre la MD y la MF es mínima, será más probable que la satisfacción con la MD sea mayor (hipótesis 6c). Como consecuencia, se proponen las siguientes hipótesis.

H6a. Un elevado grado de satisfacción con la MD en general genera una actitud positiva hacia la MD.

H6b. Un elevado grado de satisfacción con la MD en general incrementa la intención de compra de la MD en productos duraderos

H6c. Una menor percepción de diferencia en calidad entre la MD y la MF incrementa la satisfacción con la MD en general.

Por último, la implicación del individuo con la categoría de producto también ha sido objeto de estudio a la hora de analizar la intención de compra de productos con la marca de la distribución. Se ha constatado que el nivel de implicación del individuo con el producto influye sobre la decisión de compra de la MD, si bien el sentido de la relación no está claro; de hecho, se han obtenido resultados dispares, tal y como indican Miquel et. al. (2002) y corroboran Berkowitz, Bao y Allaway (2005), lo que hace pensar que la relación entre implicación e intención de compra esté condicionada por el tipo de producto. En teoría se considera que los consumidores muestran un mayor nivel de implicación con productos 
duraderos que con no duraderos o corrientes (Zaichkowsky, 1985, Laurent y Kapferer, 1992). Así pues la última hipótesis propuesta plantea que:

H7. Un nivel alto de implicación con los productos duraderos disminuye la intención de compra de productos duraderos con MD.

En conjunto, las hipótesis propuestas quedan reflejadas en el modelo que aparece en la figura 1.

Figura 1

\section{Modelo Teórico Propuesto}

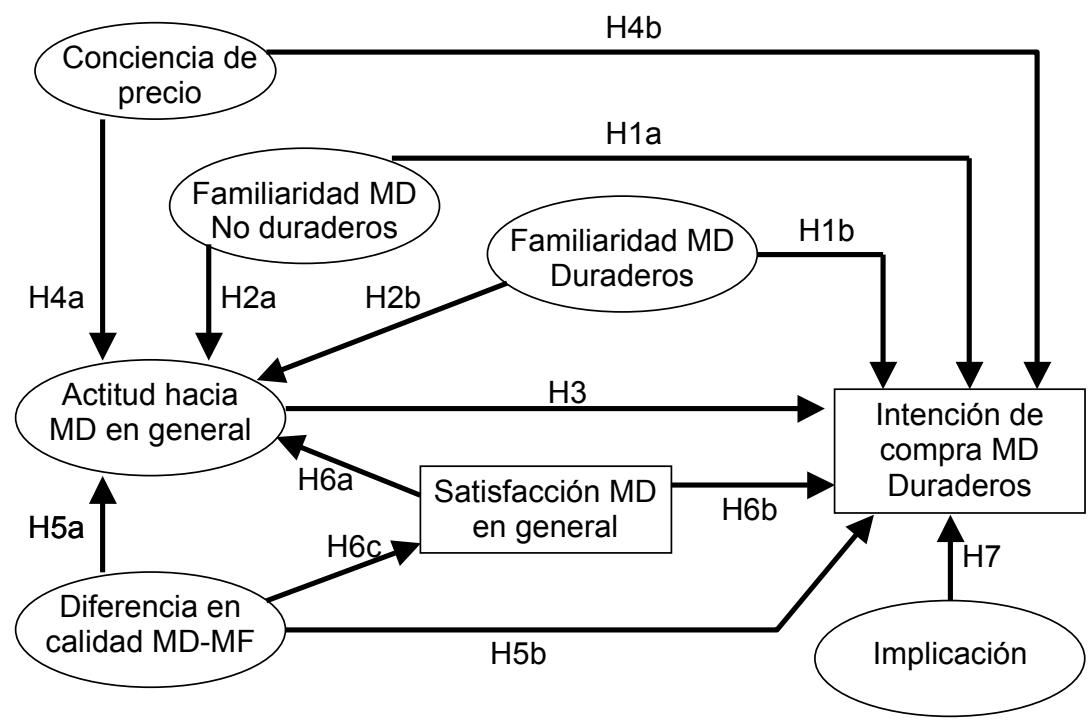

Fuente: elaboración propia

\section{METODOLOGÍA}

\subsection{Descripción de la muestra y método de obtención de la información}

Con el fin de analizar la capacidad que el modelo causal propuesto tiene para explicar la intención de compra de productos duraderos comercializados bajo la marca del distribuidor y validar las hipótesis planteadas, se seleccionaron dos categorías de productos con el fin de obtener la información necesaria sobre las variables consideradas: electrodomésticos para el hogar y productos electrónicos para el hogar. Estas categorías fueron seleccionadas atendiendo a información obtenida de los distintos informes de Euromonitor (Septiembre 2008). 
Según dichos informes, el gasto por hogar en productos y servicios para el hogar ascendió a 3.132 millones de euros en el 2007, lo que supone un incremento del gasto de más del $58 \%$ (Euromonitor, 2008). En concreto, el sector de productos electrónicos de consumo ha crecido un 20,8\% durante el periodo 2002-2007.

El incremento de hogares unipersonales suponen una gran oportunidad de negocio para un amplio rango de sectores, que incluyen proveedores de comunicación, fabricantes de electrodomésticos y productos electrónicos, la construcción o la industria del ocio (Euromonitor, 2008). A nivel global el mercado de los productos electrónicos de consumo está inmerso en un continuo de avances tecnológicos que continúan alimentando la demanda del mercado.

Durante el periodo 2002-2007, los hipermercados han descubierto que son capaces de ofrecer una amplia oferta de productos altamente tecnológicos, de forma que han desarrollado sus propias marcas en el mercado de los productos electrónicos de consumo, incrementando su presencia en sus establecimientos. La cuota de mercado en valor de la MD en productos duraderos como electrodomésticos y aparatos electrónicas se situó en el año 2007 en el 3,6\% en el caso de la línea marrón y en el 4,5\% en la línea blanca (Panel de productos duraderos GFK, 2008).

Se consideró que sería de interés seleccionar dos productos que, si bien perteneciesen a estas categorías, difiriesen en la razón por la que son adquiridos. Nos referimos a si son adquiridos principalmente por motivos utilitarios o motivos hedónicos, dado que investigaciones previas han puesto de manifiesto que la intención de compra de la marca del distribuidor difiere en un caso u otro (Sethuraman y Cole, 1999; Berkowitz, Bao y Allaway, 2005).

No todos los productos incluidos en estas categorías pueden ser fácilmente clasificados como hedónicos o utilitarios. Realmente muchos productos se encuentran en mitad de un continuo entre hedónico y utilitario (Berkowitz, Bao y Allaway, 2005). Por ello, se llevó a cabo un pretest con el fin de identificar aquellos productos que mayor diferencia mostraban, dado que cualquier producto tiene o puede tener algo de utilitario y algo de hedónico. Seleccionamos aquellos 12 productos más representativos de las dos categorías, en base al porcentaje que representa su volumen de ventas dentro de la categoría según los datos de Euromonitor (Nevera, Secadora, Lavadora, Lavavajillas, Microondas, Aire Acondicionado, Televisor, DVD, Cadena Música, Home Cinema, Ordenador de sobremesa y televisores de plasma). Sesenta consumidores valoraron en una escala de 1 nada utilitario/nada hedónico a 7 muy utilitario/muy hedónico los productos seleccionados, teniendo en cuenta que cada producto fue valorado tanto en su naturaleza hedónica como en su naturaleza utilitaria (por tanto, dos valoraciones por producto). Los doce productos fueron ordenados de mayor a menor puntuación media. Los productos seleccionados definitivamente fueron la lavadora como representante de los productos utilitarios y el televisor de plasma como producto hedónico. Los entrevistados valoraron ambos productos (Gráfico 1). De tales productos sabemos, además, que la cuota de mercado de la MD en lavadoras es el 5,5\% y en televisores de plasma es el 2,7\% (GFK, 2007). 


\section{Gráfico 1}

Resultados del pretest sobre el valor hedónico y utilitario de los productos propuestos.

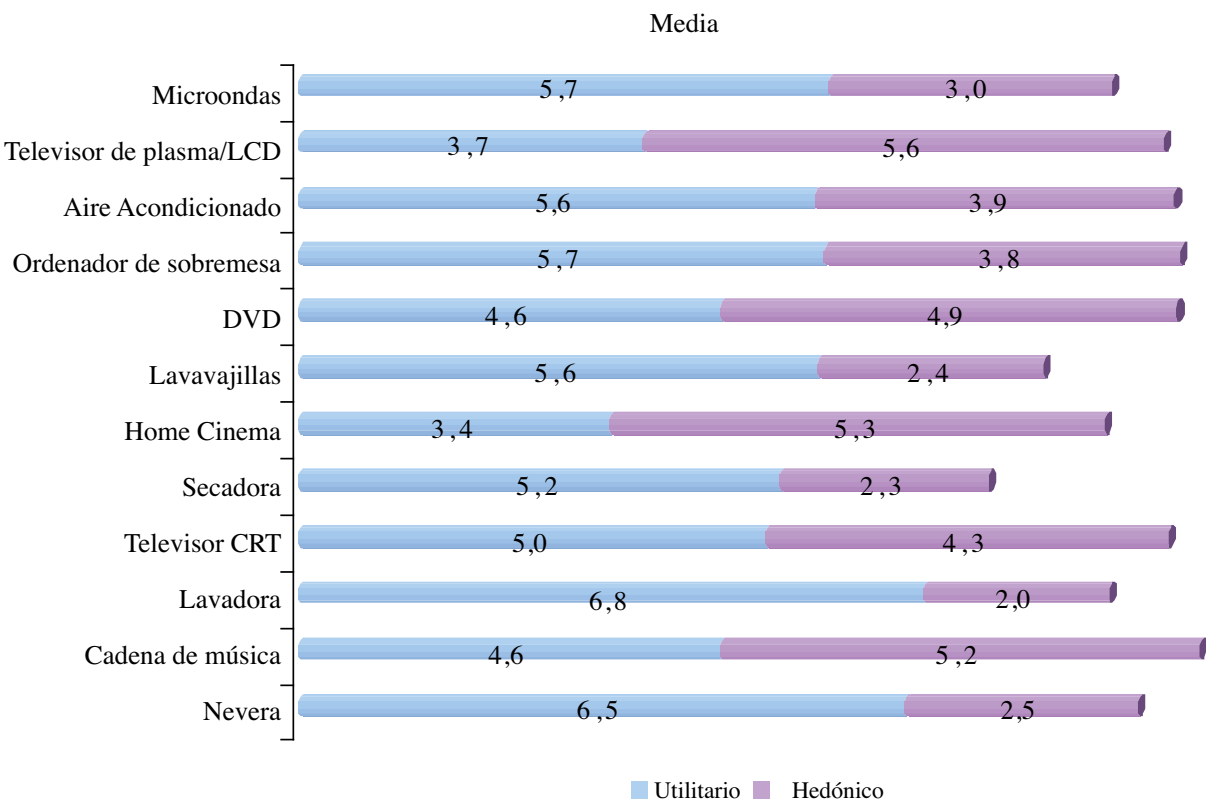

Para la obtención de los datos se diseñó un cuestionario totalmente estructurado que permitía recoger la información necesaria de cada una de las variables para la contrastación del modelo. Las distintas variables incluidas en el modelo teórico se midieron a través de escalas tipo Likert de siete puntos $(1=$ completo desacuerdo a $7=$ completo acuerdo). Todas las escalas se obtuvieron de la revisión de la literatura y por lo tanto ya han sido utilizadas en diversos trabajos. Los ítems que componen cada una de las escalas y los estudios de los que proceden se enumeran en el anexo. Adicionalmente, el cuestionario se completó con las preguntas de clasificación propias.

El universo considerado son individuos de 20 a 70 años residentes en la provincia de Valencia. El método de muestreo seleccionado fue el de cuotas en base a la edad tratando de buscar la máxima representatividad. El trabajo de campo se llevo a cabo durante el mes de julio de 2008 y se recogieron un total de 200 cuestionarios de los cuales válidos fueron 181.

\section{RESULTADOS}

Antes de entrar a contrastar las hipótesis consideramos relevante analizar a nivel descriptivo las variables estudiadas. En la tabla 1 aparecen los valores medios de las variables objeto de análisis. 
Tabla 1

Descriptivo de las variables $(1=$ Bajo/ $7=$ Alto $)$

\begin{tabular}{l|c|c}
\hline \multicolumn{1}{c|}{ Variables } & Media & Desv. Típ. \\
\hline Conciencia de precio por parte del consumidor & 5,41 & 1,41 \\
\hline Familiaridad con la marca del distribuidor en productos corrientes & 5,13 & 1,49 \\
\hline Familiaridad con la marca del distribuidor en productos duraderos & 3,02 & 1,52 \\
\hline Actitud general hacia la marca del distribuidor & 4,12 & 1,04 \\
\hline $\begin{array}{l}\text { Percepción general de diferencia en calidad entre marca del } \\
\text { distribuidor y marca del fabricante }\end{array}$ & 3,58 & 1,35 \\
\hline Satisfacción con la MD en general & 4,78 & 1,48 \\
\hline Implicación con los productos duraderos & 4,21 & 0,85 \\
\hline Intención de compra marca del distribuidor en productos duraderos & 3,79 & 1,81 \\
\hline
\end{tabular}

Es relevante destacar que la familiaridad del individuo con la marca del distribuidor en el caso de productos corrientes es, según percibe el propio individuo, relativamente alta, a diferencia de su familiaridad en el caso de productos duraderos, que sería baja. De hecho, a través de una prueba t para muestras relacionadas pudimos constatar que dicha diferencia es significativa (diferencia de media $=2,11$; valor $\mathrm{t}=15,81$; gl $=179$; sig.=0,000).

Además, el individuo está bastante satisfecho con la marca del distribuidor y posee una actitud ligeramente positiva hacia los productos con marca del distribuidor en general; considera que la diferencia en términos de calidad en los productos con marca del distribuidor frente a los productos con marca del fabricante no es elevada. En último término, la intención de compra del individuo de productos duraderos con marca del distribuidor, como se observa en la tabla 1 , no es muy alta.

\subsection{Propiedades psicométricas y contraste de hipótesis}

Para proceder a contrastar las hipótesis planteadas fue necesaria la validación previa de los instrumentos de medida utilizados, comprobándose las principales propiedades psicométricas de los mismos.

En este sentido, la fiabilidad se valoró a partir del alpha de Cronbach (Cronbach, 1951) y de la correlación ítem-total (Bagozzi, 1981) para cada una de las escalas. El análisis del alpha de Cronbach eliminando un elemento no llevó a descartar ningún ítem, pues todos superaban el umbral mínimo de 0,3 (Norusis, 1993). El alpha de Cronbach para cada una de las escalas utilizadas mostró resultados satisfactorios ya que en todos los casos presentó valores superiores a 0,7 (Nunnally, 1978).

Para contrastar la validez convergente de las escalas se realizó un análisis factorial confirmatorio sobre las seis variables latentes (Familiaridad con la marca del distribuidor 
en productos corrientes, Familiaridad con la marca del distribuidor en productos duraderos, Actitud hacia la marca del distribuidor en general, Conciencia de precio, Percepción de diferencia en calidad de la MD y la MF, e Implicación con la categoría de producto), utilizando el método de estimación ML Robust. La satisfacción con la marca del distribuidor y la intención de comprar la marca del distribuidor en productos duraderos no se incluyeron dado que se trataba de escalas con un único ítem.

Para conseguir la validez convergente fueron eliminados aquellos ítems cuyas cargas factoriales eran no significativas o inferiores a 0,60 (Bagozzi y Baumgartner, 1994; Bagozzi y Yi, 1988) o para los que el test de los multiplicadores de Lagrange sugería cargas significativas sobre un factor distinto del que eran indicadores (Hatcher, 1994). Ello supuso eliminar dos ítems de la escala "Familiaridad con la marca del distribuidor en productos corrientes", dos ítems de la escala "Familiaridad con la marca del distribuidor en productos duraderos", tres ítems de la escala "Actitud hacia la marca del distribuidor en general", dos ítems de la escala "Percepción de diferencia en calidad de la MD y la MF" y cinco ítems de la escala de "Implicación con la categoría de producto".

El modelo resultante se refleja en el cuadro 2. El valor de la Chi-cuadrado es significativo $(\alpha 2=157,18 ; \mathrm{gl}=104 ; \mathrm{p}<0,01)$, y el resto de indicadores específicos muestran un ajuste razonable $(\mathrm{BBNFI}=0,895$; $\mathrm{BBNNFI}=0,949 ; \mathrm{CFI}=0,961$; $\mathrm{IFI}=0,962 ; \mathrm{RMSEA}=0,054)$. Las cargas factoriales significativas y superiores en su totalidad a 0,60 (Bagozzi y Yi, 1988) confirman la validez convergente del instrumento propuesto.

Respecto a la fiabilidad, todos los $\alpha$ de Cronbach (Cronbach, 1951) son superiores al valor recomendado de 0,7 (Churchill, 1979). En la tabla 2 se ofrece asimismo la fiabilidad compuesta, constatándose también que su valor es superior, para todos los factores, al valor recomendado de 0,7 (Fornell y Larcker, 1981). La última columna ofrece la varianza promedio extraída, que es un indicador de la varianza capturada por un factor respecto a la varianza debida al error de medida (Fornell y Larcker, 1981). Este indicador muestra que para todos los factores se supera el valor de 0,5 que es el recomendado por Fornell y Larcker (1981). Tomados en su conjunto, todos estos indicadores demuestran evidencias suficientes de fiabilidad del instrumento de medida.

Tabla 2

Instrumento de medida; fiabilidad y validez convergente

\begin{tabular}{|c|c|c|c|c|c|c|}
\hline Factor & Indicador & $\begin{array}{l}\text { Carga } \\
\text { Estanda- } \\
\text { rizada }\end{array}$ & Valor $\mathrm{t}$ & $\begin{array}{c}\alpha \text { de } \\
\text { Cronbach }\end{array}$ & $\begin{array}{c}\text { Fiabilidad } \\
\text { Compuesta }\end{array}$ & $\begin{array}{c}\text { Varianza } \\
\text { extraída } \\
\text { promedio } \\
\text { AVE }\end{array}$ \\
\hline \multirow{3}{*}{$\begin{array}{l}\text { F1. Conciencia de } \\
\text { precio }\end{array}$} & PRECI01 & 0,825 & $12,318 * *$ & \multirow{3}{*}{0,87} & \multirow{3}{*}{0,868} & \multirow{3}{*}{0,687} \\
\hline & \begin{tabular}{|l|} 
PRECI02 \\
\end{tabular} & 0,875 & $13,097 * *$ & & & \\
\hline & PRECI03 & 0,785 & $9,837 * *$ & & & \\
\hline \multirow{2}{*}{$\begin{array}{l}\text { F2. Familiaridad } \\
\text { con la MD } \\
\text { en productos } \\
\text { corrientes }\end{array}$} & FAMCO01 & 0,891 & $13,685^{* *}$ & \multirow[b]{2}{*}{0,90} & \multirow[b]{2}{*}{0,896} & \multirow[b]{2}{*}{0,811} \\
\hline & FAMCO04 & 0,911 & $12,333 * *$ & & & \\
\hline
\end{tabular}




\begin{tabular}{|c|c|c|c|c|c|c|}
\hline Factor & Indicador & $\begin{array}{l}\text { Carga } \\
\text { Estanda- } \\
\text { rizada }\end{array}$ & Valor t & $\begin{array}{c}\alpha \mathrm{de} \\
\text { Cronbach }\end{array}$ & $\begin{array}{l}\text { Fiabilidad } \\
\text { Compuesta }\end{array}$ & $\begin{array}{c}\text { Varianza } \\
\text { extraída } \\
\text { promedio } \\
\text { AVE }\end{array}$ \\
\hline \multirow{2}{*}{$\begin{array}{l}\text { F3. Familiaridad } \\
\text { con la MD } \\
\text { en productos } \\
\text { duraderos }\end{array}$} & FAMND02 & 0,892 & $10,830 * *$ & \multirow{2}{*}{0,88} & \multirow{2}{*}{0,881} & \multirow{2}{*}{0,787} \\
\hline & FAMND03 & 0,883 & $11,153 * *$ & & & \\
\hline \multirow{2}{*}{$\begin{array}{l}\text { F4. Diferencia en } \\
\text { calidad MD y MF }\end{array}$} & CALI01 & 0,998 & $15,524 * *$ & \multirow{2}{*}{0,87} & \multirow{2}{*}{0,891} & \multirow{2}{*}{0,806} \\
\hline & CALI02 & 0,786 & $11,809 * *$ & & & \\
\hline \multirow{3}{*}{$\begin{array}{l}\text { F5. Actitud hacia } \\
\text { MD en general }\end{array}$} & АCTI03 & 0,629 & $8,630 * *$ & \multirow{3}{*}{0,80} & \multirow{3}{*}{0,799} & \multirow{3}{*}{0,573} \\
\hline & ACTI05 & 0,798 & $12,795 * *$ & & & \\
\hline & ACTI06 & 0,830 & $13,796 * *$ & & & \\
\hline \multirow{5}{*}{$\begin{array}{l}\text { F6. Implicación } \\
\text { con la categoría } \\
\text { de producto }\end{array}$} & IMPLI01 & 0,752 & $12,713 * *$ & \multirow{5}{*}{0,86} & \multirow{5}{*}{0,891} & \multirow{5}{*}{0,624} \\
\hline & IMPLI02 & 0,810 & $13,325 * *$ & & & \\
\hline & IMPLI03 & 0,881 & $16,038 * *$ & & & \\
\hline & IMPLI04 & 0,852 & $13.192 * *$ & & & \\
\hline & IMPLI06 & 0,633 & $9,842 * *$ & & & \\
\hline
\end{tabular}

$\alpha^{2}(104 \mathrm{gl})=157,18(\mathrm{p}<0,01) ; \mathrm{BBNFI}=0,895 ; \mathrm{BBNNFI}=0,949 ; \mathrm{CFI}=0,961 ; \mathrm{IFI}=0,962 ; \mathrm{RM}-$

SEA $=0,054$

$* * p<.01$

Para analizar la validez discriminante se han seguido dos procedimientos: (a) comprobar que el intervalo de confianza en la estimación de la correlación entre cada par de factores no incluye el valor 1 (Anderson y Gerbing, 1988) y (b) que la varianza promedio extraída para cada factor sea superior al cuadrado de la correlación entre cada par de factores (Fornell y Larcker, 1981). La tabla 3 muestra los resultados, lo que permite afirmar la validez discriminante del instrumento de medida propuesto.

Evaluadas las propiedades psicométricas del instrumento de medida, se procedió a estimar el modelo estructural recogido en la figura 1 que sintetiza las hipótesis planteadas. Tras realizar la identificación del modelo, éste fue estimado por el método robusto, utilizando EQS 6.1.

Tabla 3

Instrumento de medida: Validez discriminante

\begin{tabular}{c|c|c|c|c|c|c}
\hline & $\mathrm{F} 1$ & $\mathrm{~F} 2$ & $\mathrm{~F} 3$ & $\mathrm{~F} 4$ & $\mathrm{~F} 5$ & $\mathrm{~F} 6$ \\
\hline F1 & 0,687 & $0,257^{* *}$ & $0,010^{\mathrm{ns}}$ & $0,086^{* *}$ & $0,167^{* *}$ & $0,022^{\mathrm{ns}}$ \\
\hline F2 & {$[.627 ; .375]$} & 0,811 & $0,013^{\mathrm{ns}}$ & $0,063^{* *}$ & $0,281^{* *}$ & $0,004^{\mathrm{ns}}$ \\
\hline F3 & {$[.271 ;-.069]$} & {$[.281 ;-.051]$} & 0,787 & $0,071^{* *}$ & $0,008^{\mathrm{ns}}$ & $0,024^{\mathrm{ns}}$ \\
\hline F4 & {$[.466 ; .146]$} & {$[.404 ;-.100]$} & {$[.416 ; .112]$} & 0,806 & $0,205^{* *}$ & $0,004^{\mathrm{ns}}$ \\
\hline
\end{tabular}




\begin{tabular}{c|c|c|c|c|c|c}
\hline & F1 & F2 & F3 & F4 & F5 & F6 \\
\hline F5 & {$[.558 ; .248]$} & {$[.665 ; .397]$} & {$[.265 ;-.083]$} & {$[.597 ; .309]$} & 0,573 & $0,004^{\mathrm{ns}}$ \\
\hline F6 & {$[.313 ;--.015]$} & {$[.236 ;-.096]$} & {$[.321 ;-.007]$} & {$[.090 ;-.222]$} & {$[.108 ;-.236]$} & 0,624 \\
\hline
\end{tabular}

$* * \mathrm{p}<.01 ; * \mathrm{p}<.05 ; \mathrm{ns}$ no significativa

Debajo de la diagonal: intervalo de confianza para la correlación entre factores

Diagonal: varianza extraída

Sobre la diagonal: cuadrado de la correlación estimada entre los factores.

Los resultados de la estimación del modelo inicial pusieron de manifiesto ciertos problemas de ajuste de los datos, comprobándose asimismo la no significatividad de ciertas relaciones. Como señalan MacCallum, Roznowsky y Necowitz (1992) la reespecificación de un modelo basada únicamente en criterios de mejora del ajuste, pueden desembocar en un modelo final no generalizable a la población ni a otras muestras. Por ello comenzamos identificando los parámetros que pudieran eliminarse del modelo, dado que es conceptualmente menos arriesgado que añadir nuevas relaciones (Bentler y Chou, 1987). El test de Wald (Bentler, 1989) sugirió eliminar las relaciones en que se habían concretado en las hipótesis H2b, H4a, H4b, H6b, H7. Además, el modelo sugería la relación entre la "familiaridad con la marca del distribuidor en productos corrientes" y la "satisfacción con la marca del distribuidor en general". Somos conscientes de que no se deben añadir relaciones al modelo por el mero hecho de buscar un mejor ajuste; sin embargo, consideramos oportuno incluir esta nueva relación dado que, como se ha puesto de manifiesto anteriormente al analizar los descriptivos, la familiaridad con la marca del distribuidor es mucho mayor para los productos corrientes que para los productos duraderos.

Planteadas estas modificaciones el modelo revisado (tabla 4) muestra un ajuste mucho más razonable $(\alpha 2(135 \mathrm{gl})=192,111(\mathrm{p}<0,01) ; \mathrm{BBNFI}=, 888 ; \mathrm{BBNNFI}=, 953 ; \mathrm{CFI}=, 963$; $\mathrm{IFI}=, 964 ;$ RMSEA=,049).

Tal y como se desprende de la tabla 4 y su representación gráfica en la figura 2, la familiaridad con la marca del distribuidor en productos duraderos no juega ningún papel en la actitud hacia la marca del distribuidor en general. Los antecedentes directos de la intención de compra de productos duraderos con MD son cuatro: la familiaridad del consumidor con los productos con marca del distribuidor, tanto en el caso de productos corrientes como en el caso de productos duraderos, la actitud hacia la marca del distribuidor en general y la percepción de diferencias de calidad entre la marca del distribuidor y la marca del fabricante, siendo esta última variable la que más explica la intención de compra de productos duraderos con marca del distribuidor.

Por su parte, la actitud hacia la marca del distribuidor, que es el segundo antecedente en importancia de la intención de compra de productos duraderos con marca del distribuidor se ve influido por la familiaridad del consumidor con la marca del distribuidor en productos corrientes, la percepción de diferencias de calidad entre marca del distribuidor y marca de fabricante, y el nivel de satisfacción con la marca del distribuidor en general, con un peso bastante similar. Por último, el nivel de satisfacción del individuo con la marca del distribuidor en general se ve condicionado por la familiaridad que posea con la marca del 
distribuidor en productos corrientes, con un peso muy importante, así como también, por la percepción general de variabilidad de la calidad entre la marca del distribuidor y la marca del fabricante.

Tabla 4

Contraste de hipótesis modelo revisado

\begin{tabular}{|c|c|c|}
\hline HIPÓTESIS & $\begin{array}{c}\text { Carga } \\
\text { Estandarizada }\end{array}$ & Valor t \\
\hline $\begin{array}{l}\text { H1a: Familiaridad con la MD productos corrientes } \rightarrow(+) \\
\text { Intención de compra productos duraderos }\end{array}$ & $0.387 * *$ & 2.801 \\
\hline $\begin{array}{l}\text { H1b: Familiaridad con la MD productos duraderos } \rightarrow(+) \\
\text { Intención de compra productos duraderos }\end{array}$ & $0.222 *$ & 2.069 \\
\hline $\begin{array}{l}\text { H2a: Familiaridad con la MD productos corrientes } \rightarrow(+) \\
\text { Actitud hacia la marca del distribuidor }\end{array}$ & $0.283 * *$ & 2.870 \\
\hline $\begin{array}{l}\text { H2b: Familiaridad con la MD productos duraderos } \rightarrow(+) \\
\text { Actitud hacia la marca del distribuidor }\end{array}$ & n.s. & -- \\
\hline $\begin{array}{l}\text { H3: Actitud positiva hacia la marca del distribuidor } \rightarrow(+) \\
\text { Intención de compra de productos duraderos. }\end{array}$ & $0.399 *$ & 2.361 \\
\hline $\begin{array}{l}\text { H4a: Conciencia de precio por parte del consumidor } \rightarrow(+) \\
\text { Actitud hacia la marca del distribuidor }\end{array}$ & n.s & -- \\
\hline $\begin{array}{l}\text { H4b: Conciencia de precio por parte del consumidor } \rightarrow(+) \\
\text { Intención de compra de productos duraderos. }\end{array}$ & n.s. & -- \\
\hline $\begin{array}{l}\text { H5a: Percepción de la diferencia en calidad } \rightarrow(+) \text { Actitud } \\
\text { hacia la marca del distribuidor }\end{array}$ & $0.251 * *$ & 3.039 \\
\hline $\begin{array}{l}\text { H5b: Percepción de la diferencia en calidad } \rightarrow(+) \text { Intención } \\
\text { de compra de la marca del distribuidor }\end{array}$ & $0.738 * *$ & 5.958 \\
\hline $\begin{array}{l}\text { H6a: Satisfacción con la MD en general } \rightarrow(+) \text { Actitud hacia } \\
\text { la marca del distribuidor }\end{array}$ & $0.250 * *$ & 3.684 \\
\hline $\begin{array}{l}\text { H6b: Satisfacción con la MD en general } \rightarrow(+) \text { Intención de } \\
\text { compra de productos duraderos. }\end{array}$ & n.s. & -- \\
\hline $\begin{array}{l}\text { H6c: Percepción de la diferencia en calidad } \rightarrow(+) \\
\text { Satisfacción con la MD en general }\end{array}$ & $0.415 * *$ & 3.969 \\
\hline $\begin{array}{l}\text { H7: Implicación con la categoría de producto } \rightarrow(-) \text { Intención } \\
\text { de compra de productos duraderos. }\end{array}$ & n.s. & -- \\
\hline $\begin{array}{l}\text { Familiaridad con la MD productos corrientes } \rightarrow(+) \\
\text { Satisfacción con la MD en general }\end{array}$ & $0.744 * *$ & 6.594 \\
\hline \multicolumn{3}{|c|}{$\alpha^{2}(61 \mathrm{gl})=125,08(\mathrm{p}<0,01) ; \mathrm{BBNFI}=, 840 ; \mathrm{BBNNFI}=, 884 ; \mathrm{CFI}=, 909 ; \mathrm{IFI}=, 911 ; \mathrm{RMSEA}=, 07$} \\
\hline
\end{tabular}


Por último señalar que los resultados indican que ni la conciencia de precio que posea el individuo ni el nivel de implicación con la categoría de producto ejercen ninguna influencia en las variables analizadas y, por tanto, sobre la intención de compra de la marca de la distribución en estas categorías de productos.

Figura 2

Modelo final resultante

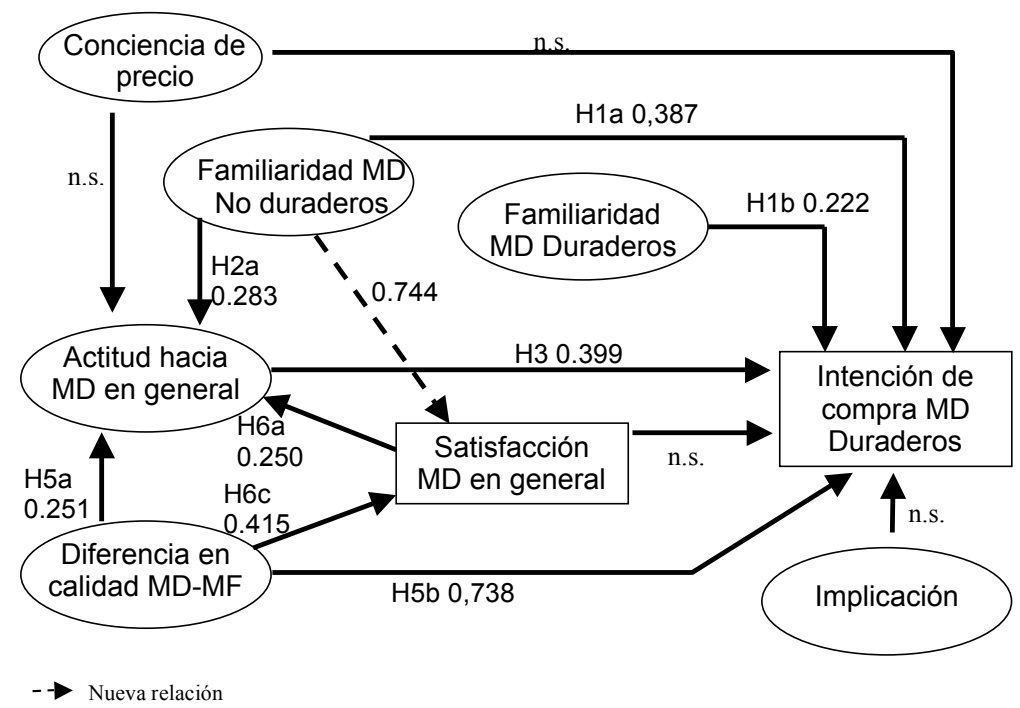

Fuente: elaboración propia

\section{CONCLUSIONES E IMPLICACIONES}

Distintas investigaciones han puesto de manifiesto que la intención de compra de los productos con marca de la distribución depende del tipo de producto (Berkowitz, Bao y Allaway, 2005; Semeijn, Van Rielm y Ambrosini, 2004; Batra y Sinha, 2000; Miquel y Caplliure, 2000; Sethuraman y Cole, 1999). Esta idea es la que ha marcado el desarrollo del presente trabajo, que analiza si algunas de las variables que identifica la literatura como determinantes de la intención de compra de productos corrientes con marca del distribuidor son de aplicación para el caso de productos duraderos con marca del distribuidor.

Las aportaciones que a nivel teórico se derivan del presente estudio son varias. La primera conclusión que puede plantearse es, por una parte, que los consumidores están menos familiarizados con la compra de productos de la distribución en productos electrónicos para el consumidor y el hogar (duraderos), que con las categorías de compra corriente de alimentación, bebidas y droguería, tal y como era de esperar; además, es la familiaridad del consumidor con la marca del distribuidor en los productos corrientes (frente a la familiari- 
dad con la marca del distribuidor en productos duraderos) la que de forma significativa más influye en la intención de compra de los productos duraderos con marca del distribuidor.

En lo relativo a la actitud hacia la marca del distribuidor en general, cabe destacar que la familiaridad de la marca del distribuidor en productos duraderos no influye en dicha actitud, a diferencia de lo que ocurre con la familiaridad de la marca del distribuidor en productos corrientes, que sí que ejerce una influencia significativa. Quizás, la generalización de la estrategia por parte de los distribuidores de incluir en su surtido sus propios productos corrientes y el importante grado de familiaridad/experiencia que el consumidor ya tiene con productos de alimentación, bebidas y droguería, sea una de las posibles razones que justifiquen dicha relación.

Además de la familiaridad con la marca del distribuidor en productos corrientes, también la percepción de posibles diferencias de calidad entre marca del distribuidor y marca de fabricante, y la satisfacción con la marca del distribuidor en general, determinan la actitud genérica hacia la marca del distribuidor, variable esta última determinante de la intención de compra de productos duraderos con marca del distribuidor. En esta línea cabe señalar que los esfuerzos realizados por los distribuidores con el fin de dotar de valor a sus marcas se está viendo recompensado, puesto que el grado de satisfacción del consumidor con estas marcas es elevado, y se ve reforzado con la familiaridad y la percepción de no existencia de diferencias importantes en cuanto a calidad entre unas y otras marcas. Ello repercute en una mejor actitud hacia estas marcas y, por tanto, en una mayor intención de compra de marca del distribuidor también en productos duraderos.

Al igual que en productos de compra corriente, se constata que existe una relación positiva entre la actitud hacia la marca del distribuidor y la intención de compra de ésta en el caso de los productos duraderos. Además, en la medida en que el consumidor no percibe diferencias entre una y otra marca, su actitud hacia la marca del distribuidor es más positiva.

Adicionalmente, es relevante señalar que no se ha obtenido ninguna relación significativa entre la variable conciencia del precio por parte del individuo y la actitud de éste hacia la marca del distribuidor, ni tampoco relación entre conciencia de precio e intención de compra de marca del distribuidor en productos duraderos. Aunque dicho resultado pueda parecer, a priori, algo extraño, es acorde y confirma las conclusiones del trabajo de Jin y Suh (2005) en relación a los productos duraderos, donde la variable conciencia del precio no tenia ninguna relación con la actitud e intención de compra de la marca de la distribución en este tipo de productos. Este aspecto es, pues, un elemento diferenciador de los determinantes de la intención de compra de marca del distribuidor en productos corrientes y en productos duraderos. De hecho, para el caso de productos de alimentación Jin y Suh (2005) demostraron que tenía un efecto pequeño aunque positivo, en consonancia con los resultados de otros trabajos previos (Burton et al, 1998; Sinha y Batra, 1999 y 2000). Una posible razón que justifique la distinta influencia de la conciencia de precio puede ser la diferente naturaleza de los productos estudiados, que hace que otras variables relativas al producto, como sus características técnicas, sean relevantes. Además, el hecho constatado de que en la actualidad las marcas del distribuidor posean una relación calidad-precio muy buena, y de que ofrezcan estándares de calidad permanentes, puede haber favorecido el hecho de que la compra de productos con marca del distribuidor ya no se considere exclusivamente una opción para los que buscan simplemente gastar poco. 
En último término y con respecto al nivel de implicación del consumidor con la categoría de producto y su relación con la intención de compra de productos duraderos con marca del distribuidor, no se ha obtenido ninguna relación, contrariamente a lo que plantean trabajos previos consultados. Aunque habría que ahondar en la búsqueda de justificación de esta nula relación, quizás la generalización de estas marcas en el mercado, y la creencia por parte del consumidor de que los productos tecnológicos son básicamente elaborados en el mismo sitio, con los mismos componentes y por marcas líderes, pueden haber llevado a que esta variable, asociada también al riesgo, no influya en la compra de estos productos cuando la variable marca del distribuidor entra en juego.

A partir de estas aportaciones teóricas se proponen implicaciones para los gestores de marca de la distribución. En primer lugar y en línea con lo que ya plantearon Sayman y Raju (2004), al distribuidor le interesa que su marca esté presente en el mayor número de categorías de producto posible, ya que eso aumentará la familiaridad del consumidor con dichas marcas y, consecuentemente, la intención de compra de éstas será mayor, independientemente de la categoría de productos de la que estemos hablando (corrientes o duraderos). En el caso en el que el distribuidor opte por una estrategia de marca privada, éste debería comunicar al consumidor la relación entre dicha marca y la cadena, especialmente si el consumidor tiene un alto nivel de satisfacción con el resto de productos con MD que comercializa el distribuidor.

Consideramos que el distribuidor debe forzar la exposición del individuo a las marcas del distribuidor, tanto fuera de la tienda como dentro. Entre las acciones que el distribuidor puede implementar fuera del establecimiento, creemos que la presencia de su propia marca, no sólo de los productos corrientes sino también de los productos duraderos, en los catálogos es una cuestión fundamental que favorecerá la familiaridad con la marca. En lo relativo a las acciones dentro del establecimiento el papel de comunicación que el personal de tienda y el merchandising realicen será crucial: una correcta visualización de los productos duraderos con marca del distribuidor en todas y cada una de las visitas del individuo al punto de venta y la información proporcionada por el personal no sólo sobre las características técnicas de los productos sino también sobre la relación entre esa marca y la enseña generará mayores niveles de familiaridad con la marca de dichos productos, aspecto importante si consideramos que la naturaleza de esta categoría de productos no favorece la familiaridad a través de la repetición de compra .

Por parte del distribuidor sería necesario, además, señalar las características más relevantes de su oferta en relación a la oferta de la competencia (productos con marca de fabricante), especialmente para el caso de los productos electrónicos, donde las características técnicas y funcionales de este tipo de productos juegan un papel determinante en la decisión de compra.

Los distribuidores deben seguir trabajando en la línea de crear valor a través de la calidad de sus productos, puesto que en la medida que consigan que sus productos sean percibidos de igual calidad o incluso mejor que los productos del fabricante lograrán mejorar su imagen e incrementar la intención de compra de éstos, tanto en el caso de productos corrientes (como ha manifestado la literatura) como duraderos.

La creación de valor de marca por parte de los distribuidores supondrá una ventaja competitiva que le permitirá extender su marca a nuevas líneas de productos por las cuales tradicionalmente no ha apostado, como puede ser la línea blanca y la línea marrón. En este 
sentido, la utilización de estrategia de marca única para todas sus categorías de productos o la asociación de su marca privada a la enseña, le permite incrementar la familiaridad del consumidor con la marca, facilitando la extensión de línea, puesto que como hemos podido comprobar, es la familiaridad con la marca de la distribución junto con la actitud general hacia este tipo de marcas, las que influyen positivamente en la compra de ésta en categorías duraderas con un mayor componente de riesgo.

Se concluye el trabajo identificando las principales limitaciones del mismo que hacen referencia, en primer lugar, al limitado marco muestral. Además, es importante considerar que los resultados presentados obedecen al análisis de un conjunto concreto de variables. El hecho de haber obviado factores también importantes como el riesgo percibido y los antecedentes de dicho riesgo, o el tipo de comprador, entre otros factores, hace que el peso de las relaciones manifiestas en este trabajo deba tomarse con cautela. Asimismo, conviene también valorar que los resultados presentados se extrapolan del análisis de tan sólo dos tipos de productos, que ni mucho menos son representantes únicos de la categoría de productos a la que pertenecen.

A partir de estas limitaciones y en aras a profundizar en este ámbito de estudio, consideramos apropiado abordar en futuros trabajos el estudio de otras variables, también utilizadas en el caso de productos corrientes, así como la ampliación a más categorías de productos duraderos a fin de poder generalizar mejor los resultados.

\section{REFERENCIAS BIBLIOGRÁFICAS}

ALBA, J.W. Y HUTCHINSON, J.W. (1987): "Dimensions of consumer expertise”, Journal of Consumer Research, vol.13, pp.411-454.

APELBAUM, E., GERSTNER, E. Y NAIK, P. (2003): "The effects of expert quality evaluations versus brand name on price premiums", Journal of Product and Brand Management, vol. 12, $\mathrm{n}^{\circ}$ 3, pp. 154-165.

BABAKUS, E., BIENSTOCK, C.C. Y VAN SCOTTER, J.R. (2004): "Linking perceived quality and customer satisfaction to store traffic and revenue growth”, Decision Sciences, vol.35, no 4 , pp.713-737.

BALTAS, G. (1997): "Determinants of store brand choice: a behavioral analysis", Journal of Product and Brand Management, vol. 6, $\mathrm{n}^{\circ}$ 5, pp. 315-324.

BATRA, R. Y SINHA, I. (2000): "Consumer-level factors moderating the success of private label brands", Journal of Retailing, vol.76, No.2, pp.175-191.

BERKOWITZ, D., BAO, Y. Y ALLAWAY, A.W. (2005): "Hispanic consumers, store loyalty and brand preference", Journal of Targeting, Measurement and Analysis for Marketing, vol.14, $\mathrm{n}^{\circ} 1$, pp. 9-24.

BOLTON, R.N. (1998): "A dynamic model of the duration of the customer's relationship with a continuous service provider: the role of satisfaction", Marketing Science, vol.17, nº 1, pp.45-65.

BUCKLIN, L.P. (1963): "Retail Strategy and The Classification of Consumer Goods", Journal of Marketing, vol.27, pp.50-55.

BURTON, S., LICHTENSTEIN, D.R., NETEMEYER, R.G. Y GARRETSON, J.A. (1998): “A Scale for Measuring attitude toward Private label Products and an Examination of Its Psychological and Behavioral Correlates", Journal of the Academy of Marketing Science, vol. 26, no4, Fall, pp.293-306.

COPELAND, M.T. (1925): Principles of Merchandising, Chicago. A.W. Shaw Company. 
COUPEY, E., IRWIN, J. R. Y PAYNE, J. W. (1998): "Product Category Familiarity and Preference Construction", Journal of Consumer Research, vol. 24, March, pp.459-468.

CRONIN, J.J.JR Y TAYLOR, S.A. (1992): "Measuring service quality: a re-examination and extension", Journal of Marketing, vol.56, n³, pp.55-68.

D'ASTOUS A. Y SAINT-LOUIS, O. (2005): "National versus store brand effects on consumer evaluation of a garment", Journal of Fashion Marketing and Management, vol. 9, no 3, pp.306-317.

DAVIES, G. (1998): "Retail brands and the theft of identity", International Journal of Retail \& Distribution Management", vol. 26, no 4, pp. 140-146.

DHAR, S.K. Y HOCH, S.J. (1997): "Why store brand penetration varies by retailer", Marketing Science, vol.16, No.3, pp.208-227.

DICK, A., JAIN, A. Y RICHARDSON, P. (1995): "Correlates of store brand proneness: Some empirical observations", Journal of Product and Brand Management, vol.4, n4, pp.15-22.

DICKSON, P.R. Y SAWYER, A.G. (1990): "The price knowledge and search of supermarket shoppers", Journal of marketing, vol.54, pp.42-53.

EUROMONITOR (2008): Bases de datos.www.portal.euromonitor.com. Consulta el 1 de Septiembre de 2008.

FERNÁNDEZ, A., GÓMEZ, M. Y RUBIO, N. (2003): "Las marcas del distribuidor y la gestión del lineal. Un análisis desde la perspectiva del fabricante" Revista Española de Investigación en Marketing- ESIC, vol. 12, pp. 3-17.

GARRETSON, J.A., FISHER, D. Y BURTON, S. (2002): "Antecedents of private label attitude and national brand promotion attitude: similarities and differences", Journal of Retailing, vol.78, pp.91-99.

GONZÁLEZ MIERES, C., DÍAZ MARTÍN, A.M. Y TRESPALACIOS GUTIÉRREZ, J.A. (2006): "Antecedents of the difference in perceived risk between store brands and national brands", $E u$ ropean Journal of Marketing, vol.40, $\mathrm{n}^{\mathrm{o}} .1 / 2$, pp. 61-82.

GUTWILLING, R. (2000): “A Household Name”, Supermarket Business, New York. 15 de junio.

HOCH, S. J. Y BANERJI, S. (1993): “When do Private Labels Succeed?”, Sloan Management Review, summer, pp. 57-67.

HOCH, S. J. (1996): "How should national brands think about private labels?", Sloan Management Review, vol.37, No.2, pp.89-102.

HOLBROOK, M.B. Y HOWARD, J.A. (1976): "Frequently Purchased Nondurable Goods and Services", en Selected Aspects of Consumer Behavior, un resumen de The Perspective of Different Disciplines, preparado por The National Science Foundation, US Government Printing Office. Citado por Wind (1982), ob.cit.

HOLTON, R.H. (1958): “The Distinction between Convenience Goods, Shopping Goods, and Specialty Goods", Journal of Marketing, vol.23.

JIN, B. Y SUH, Y.G. (2005): "Integrating effect of consumer perception factors in predicting private brand purchase in a Korean discount store context", The Journal of Consumer Marketing, vol.22, no $2 / 3$, pp. 62 .

KELMECI-SCHNEIDER, G. (2004): Handelsmarken im interkulturellen Vergleich: Einstellungen in Deutschland und in der Türkei am Bispiel des LEH. Handelsforschung 2004, BBE, Cologne, pp.249-266.

MÉNDEZ, J.L., OUBIÑA, J. Y ROZANO, M. (2000): "Influencia de las marcas de distribuidor en las relaciones fabricante-distribuidor", Distribución y Consumo. $\mathrm{n}^{\circ}$ 53, pp. 55-74.

MIQUEL, S. Y CAPLLIURE, E.M. (2000): “¿De qué forma el nivel de implicación influye en la compra de la marca del distribuidor?, Revista Española de Investigación de Marketing ESIC, vol.4, n², pp.109-136.

MIQUEL, S., CAPLLIURE, E.M. Y ALDAS, J. (2002): "The effect of personal involvement on the decision to buy store brands", Journal of Product \& Brand Management, vol.11, No.1, pp.6-16. 
MIRANDA, M. J. Y JOSHI, M. (2003): "Australian Retailers Need to Engage with Private Labels to Achieve Competitive Difference", Asia Pacific Journal of Marketing and Logistics, vol.15, No3, PP.34-47.

NANDAN, S. Y DICKINSON, R. (1994): "Private Brands: Major Brand Perspective", Journal of Consumer Marketing, vol. 11, nº, pp. 18-28.

NARASIMHAN, C. Y WILCOX, R.T. (1998): "Private labels and the channel relationship: a crosscategory analysis", Journal of Business, vol.71, No.4, pp.573-600.

NIELSEN (2008): Estudio realizado para la PLMA, en, www.plmainternacional.com. Consulta el 1 de Septiembre de 2008.

OLIVER, R.L. (1980): "A cognitive model of the antecedents and consequences of satisfaction decisions", Journal of Marketing Research", vol.17, pp.460-469.

OLSEN, S.O. (2002): "Comparative evaluation and the relationship between quality, satisfaction, and repurchase loyalty", Journal of the Academy of Marketing Science, vol.30, n⿳3, pp.240-249.

OUBIÑA, J., RUBIO, N. Y YAGÜE, M.J. (2006): "Strategic management of store brands: an analysis from the manufacturer's perspective", International Journal of Retail \& Distribution Management, vol.34, $\mathrm{n}^{\circ} 10$, pp. 742-760.

PAPPU, R. Y QUESTER, P. (2006): “Does customer satisfaction lead to improved brand equity? An empirical examination of two categories of retail brands", The Journal of Product and Brand Management, vol.15, $\mathrm{n}^{\circ} 1$, pp. 4-14.

PARASURAMAN, A., ZEITHAML, V.A. Y BERRY, L.L (1994): "Reassesment of expectations as a comparison standard in measuring service quality: implications for further research", Journal of Marketing, vol.58, $\mathrm{n}^{\circ} 1$, pp.111-124.

PLMA (2008): Anuario Internacional de la marca del distribuidor 2008. www.plmainternacional. com. Consulta el 1 de Septiembre de 2008.

PUTSIS, W.P.JR. Y DHAR, R. (2001): "An empirical analysis of the determinants of category expenditure", Journal of Business Research, vol.52, pp.277-291.

PUELLES-GALLO, M. Y MANZANO-ANTON, R. (2009): "Actualidad de las marcas de distribuidor en las grandes superficies especializadas no alimentarias en España”, Distribución y Consumo, noviembre-diciembre, pp. 38-45.

RECIO, M. Y ROMÁN, M.V. (1999): "Posibilidades de gestión estratégica de las marcas de distribuidor", Distribución y Consumo, abril-mayo, pp. 13-29.

RICHARDSON, P. JAIN, A.K. Y DICK, A.S. (1996): "The influence of store aesthetics on evaluation of private label brands", Journal of Product and Brand Management, vol. 5, $\mathrm{n}^{\circ}$ 2, pp.19-28.

RICHARDSON, P. (1997):"Are store brands perceived to be just another brand?", Journal of Product and Brand Management, vol. 6, n 6, pp.388-404.

ROEST, H. Y PIETERS, R. (1997): "The nomological net of perceived service quality", International Journal of Service Industry Manaangement", vol.8, nº, pp.336-351.

SAYMAN, S. Y RAJU, J. S. (2004): "Investigating the Cross-Category Effects of Store Brands", Review of Industrial Organization, vol. 24, $\mathrm{n}^{\circ} 2$, pp. 129-141.

SEMEIJN, J., VAN RIEL, A.C.R. Y AMBROSINI, A.B. (2004): "Consumer evaluations of store brands: effects of store image and product attributes", Journal of Retailing and Consumer Services, vol.11, No.4, pp.247-258.

SETHURAMAN, R. (1992): "Understanding Cross-Category Differences in Private Label Shares of Grocery Products", Marketing Science Institute Working Paper no.92-128. Cambridge. MA. Marketing Science Institute.

SETHURAMAN, R. Y COLE, C. (1997): "Why Do Consumers Pay More for National Brands Than for Store Brands?", Marketing Science Institute Working Paper no.97-126. Cambridge. MA. Marketing Science Institute.

SHANNON, R. Y MANDHACHITARA, R. (2005): "Private-label grocery shopping attitudes and behaviour: A cross-cultural study", Brand management, vol.12, nº, pp.461-474. 
SINHA, I. Y BATRA, R. (1999): "The effect of consumer price consciousness on private label purchase", International Journal of Research in Marketing, vol.16, No.3, pp.237-251.

STEINER, R. L. (2004): "The Nature and Benefits of National Brand/Private Label Competition", Review of Industrial Organization, vol.24, n², pp. 105-127.

URIOL, E. (2004): "El gran comercio especializado gana la batalla al hiper", Cinco días, 14 de Enero de 2004.

VAHIE, A. Y PASWAN, A. (2006): "Private label brand image: its relationship with store image and national brand", International Journal of Retail \& Distribution Management, vol.34, nº1, pp. 67-84.

WIND, Y.J. (1982): Product Policy: Concepts, Methods and Strategy. Addison-Wesley Publishing Company. Capítulo 4, pp.67-74.

ZIELKE, S. Y DOBBELSTEIN, T. (2007): "Customers' willingness to purchase new store brands", The Journal of Product \& Brand Management, vol.16, n², pp. 112-121. 


\section{ANEXO. INSTRUMENTOS DE MEDIDAS DE LAS VARIABLES EXPLICATI- VAS DE LA INTENCIÓN DE COMPRA EN PRODUCTOS DURADEROS}

\begin{tabular}{|c|c|c|c|}
\hline Escala & \multicolumn{2}{|c|}{ Ítems } & Fuente secundaria \\
\hline $\begin{array}{l}\text { Actitud hacia } \\
\text { la marca del } \\
\text { distribuidor } \\
\text { en general }\end{array}$ & \multicolumn{2}{|c|}{$\begin{array}{l}\text { a. Comprar la marca del distribuidor me hace sentir bien } \\
\text { b. Me encanta que la marca del distribuidor esté disponible en el tipo } \\
\text { de productos que compro } \\
\text { c. Para muchos productos, la mejor compra normalmente es la marca } \\
\text { del distribuidor } \\
\text { d. En general, la marca del distribuidor ofrece productos de inferior } \\
\text { calidad } \\
\text { e. Teniendo en cuenta el valor de lo que pago prefiero la marca del } \\
\text { distribuidor a la marca del fabricante } \\
\text { f. Cuando compro la marca del distribuidor, siempre siento que salgo } \\
\text { ganando }\end{array}$} & $\begin{array}{l}\text { Burton, Lichtenstein, } \\
\text { Netemeyer y } \\
\text { Garretson (1998) }\end{array}$ \\
\hline $\begin{array}{l}\text { Familiaridad } \\
\text { con la } \\
\text { marca del } \\
\text { distribuidor* }\end{array}$ & \multicolumn{2}{|c|}{$\begin{array}{l}\text { a. Tengo mucha experiencia en la compra de productos con marca del } \\
\text { distribuidor } \\
\text { b. Conozco bien la oferta de productos con marca del distribuidor } \\
\text { c. Las marcas del distribuidor me son muy familiares } \\
\text { d. A menudo compro productos con la marca del distribuidor }\end{array}$} & $\begin{array}{l}\text { González, Díaz y } \\
\text { Trespalacios (2006) } \\
\text { Dick y Richardson } \\
\text { (1995) }\end{array}$ \\
\hline $\begin{array}{l}\text { Diferencia } \\
\text { en calidad } \\
\text { percibida } \\
\text { entre la MD } \\
\text { y la MF }\end{array}$ & \multicolumn{2}{|c|}{$\begin{array}{l}\text { a. La marca del fabricante y la marca del distribuidor tienen } \\
\text { prácticamente la misma calidad } \\
\text { b. No creo que la marca del distribuidor sea de menor calidad que la } \\
\text { marca del fabricante } \\
\text { c. No hay mucha diferencia en términos de calidad entre la marca del } \\
\text { fabricante y la marca del distribuidor } \\
\text { d. Creo que la marca del distribuidor es de mayor calidad que algunas } \\
\text { marcas }\end{array}$} & $\begin{array}{l}\text { Batra y Sinha (2000) } \\
\text { Dick y Richardson } \\
\text { (1995) } \\
\text { González, Díaz y } \\
\text { Trespalacios (2006) } \\
\text { Shannon y } \\
\text { Mandhachitara } \\
(2005)\end{array}$ \\
\hline $\begin{array}{l}\text { Implicación } \\
\text { con la } \\
\text { categoría de } \\
\text { producto }\end{array}$ & $\begin{array}{l}\text { Que no me importa nada } \\
\text { Irrelevante } \\
\text { Que no tiene ningún valor en mi vida } \\
\text { Que no significa nada para mi } \\
\text { Que no necesito } \\
\text { En absoluto interesante } \\
\text { Que no me llama la atención } \\
\text { Que no me fascina } \\
\text { Que no me emociona } \\
\text { Que no me interesa }\end{array}$ & $\begin{array}{l}\text { Que me importa mucho } \\
\text { Relevante } \\
\text { Que tiene mucho valor en } \\
\text { mi vida } \\
\text { Que significa mucho para mi } \\
\text { Que necesito } \\
\text { Muy interesante } \\
\text { Que me llama la atención } \\
\text { Que me fascina } \\
\text { Que me emociona } \\
\text { Que me interesa }\end{array}$ & Zaichkowsky (1994) \\
\hline $\begin{array}{l}\text { Conciencia } \\
\text { de precio }\end{array}$ & \multicolumn{2}{|c|}{$\begin{array}{l}\text { Suelo comparar los precios de varias marcas antes de elegir una en } \\
\text { particular. } \\
\text { Independientemente de que sea un producto de alto precio o de bajo } \\
\text { precio, siempre comparo los precios del producto antes de comprarlo. } \\
\text { Para mi es importante conseguir el mejor precio en los productos que } \\
\text { compro. }\end{array}$} & $\begin{array}{l}\text { Burton et al, } 1998 \\
\text { Sinha y Batra, } 1999 \\
\text { y } 2000 ; \text { Ailawadi, } \\
\text { Neslin y Gedenk, } \\
2001\end{array}$ \\
\hline $\begin{array}{l}\text { Satisfacción } \\
\text { con la MD } \\
\text { en general }\end{array}$ & \multicolumn{2}{|c|}{$\begin{array}{l}\text { En general, siempre he quedado satisfecho con los productos que } \\
\text { he comprado con marca del distribuidor }\end{array}$} & Elaboración propia \\
\hline $\begin{array}{l}\text { Intención de } \\
\text { compra de } \\
\text { MD }\end{array}$ & \multicolumn{2}{|c|}{ ¿Compraría usted ___ con marca del distribuidor? } & Elaboración propia \\
\hline
\end{tabular}

* Esta escala de familiaridad con la marca del distribuidor se ha empleado tanto para productos duraderos como no duraderos. 
